\title{
Effects of hyperventilation on pattern-reversal visual evoked potentials in patients with demyelination
}

\author{
H D DAVIES, W M CARROLL, F L MASTAGLIA \\ From the Departments of Neurology and University Department of Medicine, Queen Elizabeth II Medical \\ Centre, Perth, Western Australia
}

SUMMARY The effects of hyperventilation on the pattern-reversal visual evoked potential (VEP) were studied in seven normal subjects and 13 multiple sclerosis patients with visual pathway involvement. Significantly greater reductions in P100 latency occurred in the multiple sclerosis patients than in controls and normalisation of the half-field response topography occurred in one patient after hyperventilation. The VEP changes are attributed to improved impulse transmission in demyelinated fibres in the visual pathway as a result of the alkalosis and changes in ionised calcium levels induced by hyperventilation.

Hyperventilation, alkalosis and hypocalcaemia have been shown to bring about a transient improvement in neurological deficits such as visual impairment, nystagmus and ocular paresis in patients with central nervous system demyelination. ${ }^{1}$ It has been suggested on theoretical grounds that this improvement is the result of changes in nerve fibre excitability and enhanced conduction in demyelinated nerve fibres. ${ }^{23}$

In the present study, we have recorded patternreversal visual evoked potentials (VEPs) before and after hyperventilation in patients with multiple sclerosis and known visual pathway involvement to determine whether there is any evidence that this procedure improves conduction in the demyelinated visual pathway.

\section{Subjects and methods}

\section{Subjects}

Seven staff members, aged from 20 to 44 years, all of whom had normal vision, served as control subjects. Thirteen patients with multiple sclerosis who were known to have clinical and/or VEP evidence of visual pathway involvement, and all of whom fulfilled McDonald \& Halliday's ${ }^{4}$ criteria for clinically definite multiple sclerosis, were selected for the study (table). Visual symptoms were stable in all patients and none had Uhthoff's phenomenon.

Address for reprint requests: Professor FL Mastaglia, University Department of Medicine, Queen Elizabeth II Medical Centre, Nedlands, WA 6009, Australia.

Received 15 November 1985 and in revised form 19 February 1986. Accepted 24 February 1986
Visual evoked potentials

Monocular VEPs were recorded from eight occipital electrodes arranged in transverse and sagittal chains, and each referred to $\mathrm{Fz}$ (10-20 system). The midline electrode of the transverse chain of five electrodes was positioned $5 \mathrm{~cm}$ above the inion and the other four electrodes at 5 and $10 \mathrm{~cm}$ to either side. The remaining three were positioned at the inion, $2.5 \mathrm{~cm}$ above and $5 \mathrm{~cm}$ below this point. The checkerboard stimulus was displayed on a high resolution CRT (HewlettPackard 1321A) by a purpose-built pattern generator $(\mathrm{Mr}$ JR Pitman, MRC External Staff, National Hospital, Queen Square). The mean luminance of $50^{\prime}$ black and white checks was 10 candelas $\mathrm{m}^{-2}$ (contrast 0.93 ) and the pattern was reversed in $10 \mathrm{~ms}$ every $605 \mathrm{~ms}$. $300 \mathrm{~ms}$ of post-stimulus EEG was collected following each of 200 reversals after differential amplification (band-pass $1-500 \mathrm{~Hz}$ at $-3 \mathrm{db}$ ) and was averaged on a PDP $11 / 23$ computer with a sampling rate of $500 \mathrm{~Hz}$. Responses were obtained to full-field $\left(26^{\circ} \times\right.$ $\left.19^{\circ}\right)$ and vertical half-field $\left(13^{\circ} \times 19^{\circ}\right)$ stimulation. When appropriate, subjects wore spectacles to correct for refractive errors. The P100 latency and peak-to-peak amplitude were cursored after visual inspection of waveforms recorded from the midline channel electrode for full-field stimulation and from the $5 \mathrm{~cm}$ ipsilateral channel for half-field stimulation. In four of the 13 multiple sclerosis patients only monocular full-field VEPs were recorded from a single midoccipital electrode $(\mathrm{Oz})$ referred to $\mathrm{Cz}$.

\section{Experimental procedure}

Baseline monocular full-field and half-field VEP responses were first recorded. In each subject one half-field or full-field (in those in whom half-field recordings were not performed) which gave an abnormal but still clearly discernible VEP was selected and tested for reproducibility prior to commencement of hyperventilation. End-tidal $\mathrm{pCO}_{2}$ was monitored using a Hewlett-Packard capnometer (Model 47210A) prior 
Table Clinical details in the 13 multiple sclerosis patients showing the findings in the eye under study. The last four patients had only monocular full-field VEPs recorded

\begin{tabular}{|c|c|c|c|c|}
\hline Patient & $\begin{array}{l}\text { Visual } \\
\text { symptoms }\end{array}$ & $\begin{array}{l}\text { Visual } \\
\text { acuity }\end{array}$ & $\begin{array}{l}\text { Visual } \\
\text { field defect }\end{array}$ & $\begin{array}{l}\text { Optic disc } \\
\text { pallor* }\end{array}$ \\
\hline $\begin{array}{c}1 \text { (GB) } \\
2 \text { (DB) } \\
3 \text { (MG) } \\
4 \text { (KP) } \\
5 \text { (CM) } \\
6 \text { (BH) } \\
7 \text { (SG) } \\
8 \text { (LA) } \\
9 \text { (AD) } \\
10 \text { (GR) } \\
11 \text { (GC) } \\
12 \text { (IK) } \\
13 \text { (DB) }\end{array}$ & $\begin{array}{l}\text { BOV } \\
\text { BOV } \\
\text { Nil } \\
\text { BOV } \\
\text { BOV } \\
\text { BOV } \\
\text { BOV } \\
\text { Nil } \\
\text { BOV } \\
\text { LOV } \\
\text { BOV } \\
\text { BOV } \\
\text { BOV }\end{array}$ & $\begin{array}{l}6 / 24 \\
6 / 9 \\
6 / 9 \\
6 / 18 \\
6 / 60 \\
6 / 9 \\
6 / 9 \\
6 / 6 \\
6 / 5 \\
6 / 9 \\
6 / 5 \\
6 / 24 \\
6 / 18\end{array}$ & $\begin{array}{l}\text { NT } \\
\text { Nil } \\
\text { NT } \\
\text { Rel CS } \\
\text { CS } \\
\text { Nil } \\
\text { Rel CS } \\
\text { Nil } \\
\text { Nil } \\
\text { Nil } \\
\text { Nil } \\
\text { Rel CS } \\
\text { NT }\end{array}$ & $\begin{array}{l}\text { NT } \\
2 \\
\text { NT } \\
2 \\
3 \\
2 \\
3 \\
3 \\
2 \\
2 \\
1 \\
3 \\
\text { NT }\end{array}$ \\
\hline
\end{tabular}

BOV-blurring of vision; LOV - loss of vision; Rel CS - relative central scotoma; *-disc pallor graded on a scale of 1 (minimal) to 4 (gross); NT-not tested.

to, continuously during the period of hyperventilation, and after completion of hyperventilation. Subjects were instructed to breath deeply, once every 2-3 seconds for 3-5 minutes until the $\mathrm{pCO}_{2}$ had decreased to less than $25 \mathrm{~mm} \mathrm{Hg}$. The selected half-field or full-field VEP was rerecorded 1.5 minutes after the onset of hyperventilation, at the end of the period of hyperventilation, and again after the $\mathrm{pCO}_{2}$ had returned to the baseline level. Room temperature was constant at $22^{\circ} \mathrm{C}$ for all recordings.

\section{Results}

During hyperventilation, the $\mathrm{pCO}_{2}$ values fell in all

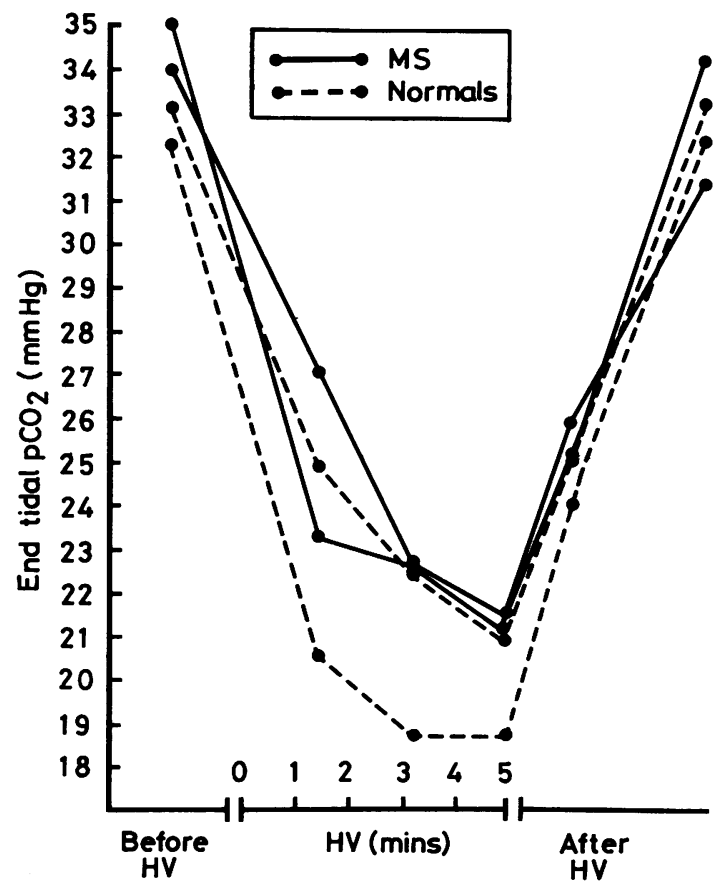

Fig 1 Typical serial end-tidal $\mathrm{pCO}_{2}$ values in two multiple sclerosis patients and two normal control subjects before, during and after hyperventilation.

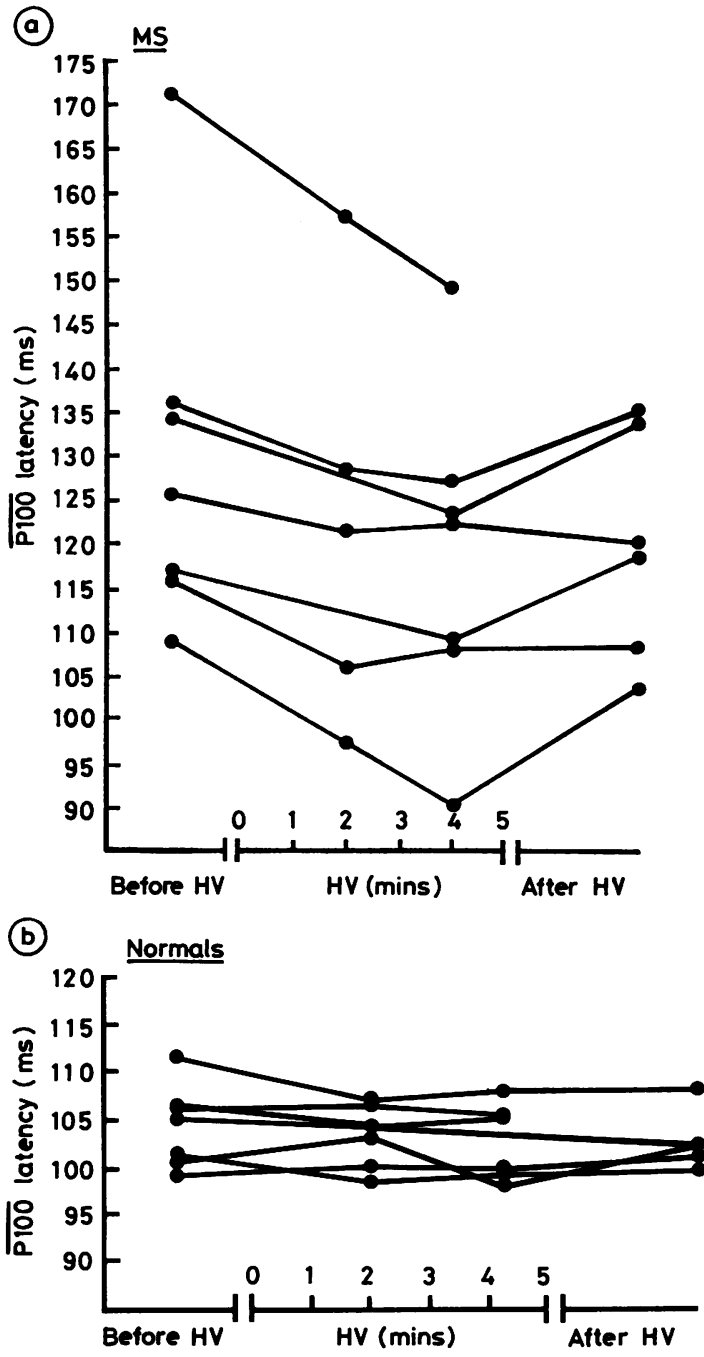

Fig 2 Monocular half-field $\overline{P 100}$ latencies before, during and after hyperventilation in seven multiple sclerosis patients (a) and seven normal control subjects (b). 
(a) Normal

JH 925 years

$30 / 10 / 83$

VAL $6 / 6$


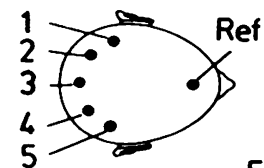

(b) $M S$

SG 936 years

\section{$2 / 11 / 83$}

VAR $6 / 9$

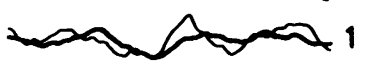

$\sim^{2}$


(c) $\mathrm{MS}$

GB of 44 years
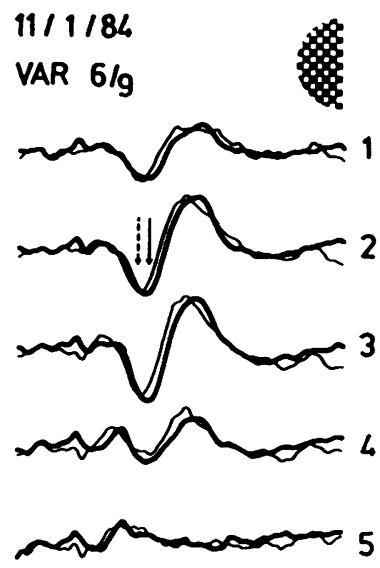

$5 \mu V^{-}$
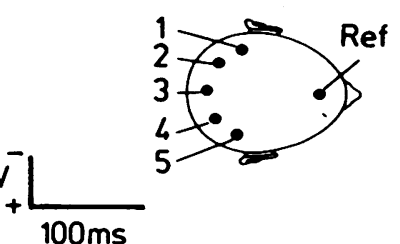

Fig 3 Monocular half-field VEPs recorded before (heavy tracing) and immediately after (light tracing) hyperventilation from a normal control subject $(a)$ and two multiple sclerosis patients $(b$ and $c$ ). The macular-derived P100 component is seen over the scalp ipsilateral to the stimulated half-field and is identified by the solid (before hyperventilation) and broken (after hyperventilation) arrows. In the control subject, the waveform topography and P100 latency (107 ms) remains unchanged. In b the delayed left half-field P100 latency of $136 \mathrm{~ms}$ decreased to $127 \mathrm{~ms}$, and in $\mathrm{c}$ the minimally delayed left half-field P100 latency decreased from $116 \mathrm{~ms}$ to $110 \mathrm{~ms}$. Note that the recordings from 5 transverse electrodes only are shown here and in fig 4.

subjects and returned to baseline levels after 10-30 minutes (fig 1). In multiple sclerosis subjects the mean fall was $18 \mathrm{~mm} \mathrm{Hg}$ (range $17-19 \mathrm{~mm} \mathrm{Hg}$ ) compared with a mean fall of $17 \mathrm{~mm} \mathrm{Hg}$ (range 13-24 $\mathrm{mm} \mathrm{Hg}$ ) in controls.

The major change in the VEPs from the multiple sclerosis subjects was a decrease in $\overline{\mathrm{P} 100}$ latency (fig $2 \mathrm{a}$ and $3 \mathrm{~b}-\mathrm{c}$ ). Of the seven multiple sclerosis patients with delayed half-field $\overline{\mathrm{P} 100}$ components, hyperventilation resulted in a mean fall in latency of $10.4 \mathrm{~ms}$ (range -3 to $-22 \mathrm{~ms}$ ) which was significantly greater than the mean fall of $1.4 \mathrm{~ms}(+1$ to -3$)$ in the seven control subjects $(p<0.01)$ (fig 3a-c). Two multiple sclerosis patients (cases 5 and 6) had half-field VEPs which were dominated by paramacular subcomponents. ${ }^{56}$ In Case 6, the latency of the paramacular $\overline{\mathrm{N} 105}$ component decreased by $5 \mathrm{~ms}$ and in case 5 the subcomponent topography was altered with hyperventilation resulting in the appearance of a macular $\overline{\mathrm{P} 100}$ component. All four multiple sclerosis patients who had only monocular full-field recordings showed a decrease in the latency of the major positivity, with a mean fall of $6 \mathrm{~ms}$ (range -3 to $-10 \mathrm{~ms}$ ). There was no significant correlation between the degree of latency change and the pre-hyperventilation latency: that is, the longest latencies did not always show the largest decrements (see fig 2a). Changes in VEP amplitude after hyperventilation were minor and bidirectional, without a consistent pattern in either the multiple sclerosis patients or control subjects. Normal or prolonged latency half-field $\overline{\mathrm{P} 100}$ components and full-field late positivities showed both amplitude increments and decrements in different subjects. In all multiple sclerosis patients the changes were transient, $\overline{\mathrm{P} 100}$ (half-field) and late positivity (full-field) laten- 
LA $\$ 28$ years

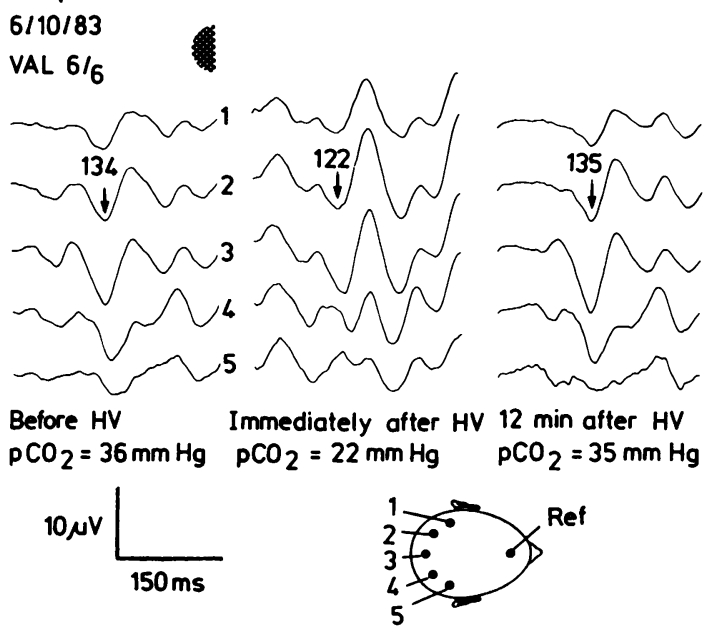

Fig 4 Monocular left half-field VEPs recorded from a 28-year-old multiple sclerosis patient before, immediately after and 12 minutes after cessation of hyperventilation $(\mathrm{HV})$. The macular-derived $\overline{P 100}$ component latencies are shown above the arrows identifying this component. The delayed $\overline{P 100}$ component latency decreased by $12 \mathrm{~ms}$ with the $14 \mathrm{~mm} \mathrm{Hg}$ drop in end-tidal $\mathrm{pCO}_{2}$ immediately after hyperventilation and then returned to the pre-hyperventilation latency $(135 \mathrm{~ms})$ in parallel with the subsequent increase in end-tidal $\mathrm{pCO}_{2}$

cies and the altered subcomponent topography all reverting to baseline values after hyperventilation (for example, see fig 4).

\section{Discussion}

The major findings of the present study were that hyperventilation resulted in a significant reduction of the $\overline{\mathbf{P} 100}$ latency and a more normal VEP waveform and topography in some patients with visual pathway demyelination. The implication of these findings is that hyperventilation leads to improved impulse transmission in areas of demyelination and thereby to a more physiological pattern of cortical activation by pattern stimulation. A primary action at retinal or cortical level is less likely. The changes in $\overline{\mathbf{P} 100}$ latency, the change from a "paramacular" to a "macular" half-field response, and the increased $\overline{\mathrm{P} 100}$ amplitude in some multiple sclerosis subjects points to enhanced conduction particularly in fibres subserving the central $5^{\circ}$ of vision which are largely responsible for the macular $\overline{\mathrm{P} 100}$ component of the VEP. ${ }^{78}$ The lack of a uniform change in $\overline{\mathrm{P} 100}$ amplitude contrasts sharply with the changes in $\overline{P 100}$ latency and probably reflects the variable mix of degrees of conduction block among fibres subserving central vision and the effects of altering conductivity in these fibres on the interaction of macular and paramacular subcomponents of the VEP. ${ }^{58}$

The effects of hyperventilation may be mediated by a number of factors. Both the reduction in $\mathrm{pCO}_{2}$ and the rise in extracellular $\mathrm{pH}$ which accompany hyperventilation are known to enhance neural excitability in peripheral nerve fibres ${ }^{910}$ and on theoretical grounds should also increase the safety factor for transmission in central fibres. ${ }^{2}$ In addition, because of increased binding of calcium ions to proteins when alkalosis occurs, there is a secondary reduction in serum ionised calcium levels. ${ }^{11}$ This would not normally be expected to affect the central nervous system because of the existence of a potent blood-brain and blood-CSF barrier for calcium ions. ${ }^{12}$ However, as suggested by Davis et al, ${ }^{1}$ it is conceivable that such a barrier is defective in areas of demyelination and that reduced ionised calcium levels could therefore also increase axonal excitability and the safety factor for transmission in demyelinated central nerve fibres. This suggestion is supported by the clinical observation of improvement in visual and ocular motor signs in multiple sclerosis patients after intravenous infusion of sodium EDTA which binds calcium ions ${ }^{1}$ and significant, though transient, reductions in VEP latencies during intravenous infusion of the calcium channel blocker verapamil. ${ }^{13}$ It is unlikely that the VEP changes in the multiple sclerosis subjects were related to changes in cerebral blood flow induced by hypocapnia during hyperventilation. ${ }^{14}$

The effects of hyperventilation on conduction in demyelinated fibres are, for the most part, the converse of those resulting from increased temperature. Although experimental models of conduction in demyelinated fibres have shown that both absolute conduction and conduction velocity are temperaturedependent, the net effect of an elevated temperature tends towards more complete conduction block. ${ }^{15}$ This effect was also demonstrated by VEP studies in multiple sclerosis patients where a diminished VEP amplitude was the principal change. ${ }^{1617}$ In the present study the exact mechanism for the reduction in $\overline{P 100}$ latency and the improved VEP waveforms and amplitude in some patients is not clear, but it is not necessary to postulate that the conduction velocity must have increased. Whilst slowing of conduction has been demonstrated in demyelinated fibres in the dorsal column and peripheral nervous system, it has not been proved to be the sole basis for the prolongation of the VEP latency in multiple sclerosis. ${ }^{18} 19$ Experimental studies have shown that focal demyelinating lesions of the cat optic nerve result in conduction block, increased refractory period of transmission and failure of single nerve fibres to faithfully transmit impulses. ${ }^{2021}$ Modest increments in 
conduction times were also found in these studies but were insufficient to account for the degree of pattern VEP delay (Carroll, Levick and Mastaglia, unpublished observations). Thus, reversal of conduction block, improved transmission of impulse trains in demyelinated fibres and hence a more coherent pattern of cortical activation are likely to underlie the transient reduction in $\overline{\mathrm{P} 100}$ latency and other VEP changes seen after hyperventilation in the present study.

The authors are grateful to Mr GW Thickbroom for his help in this study and to Mrs P McBryde for secretarial assistance.

\section{References}

1 Davis FA, Becker FO, Michael JA, Sorensen E. Effect of intravenous sodium bicarbonate, disodium editate ( $\mathrm{Na}_{2} \mathrm{EDTA}$ ), and hyperventilation on visual and oculomotor signs in multiple sclerosis. J Neurol Neurosurg Psychiatry 1970;33:723-32.

2 Davis FA, Schauf CL. The pathophysiology of multiple sclerosis: a theoretical model. In: Klawans HL, ed. Models of Neurological Diseases. Amsterdam: Excerpta Medica 1974:83-107.

3 Rogart RB, Ritchie JM. Pathophysiology of conduction in demyelinated nerve fibers. In: Morell P, ed. Myelin. New York: Plenum Press 1977:353-82.

4 McDonald WI, Halliday AM. Diagnosis and classification of multiple sclerosis. $\mathrm{Br}$ Med Bull 1977;33:4-8.

5 Halliday AM, Barrett G, Blumhardt LD, Kriss A. The macular and paramacular subcomponents of the pattern evoked response. In: Lehmann D, Callaway E, eds. Human Evoked Potentials. Plenum Publishing 1979:135-51.

6 Carroll WM, Halliday AM, Kriss A. Improvements in the accuracy of pattern visual evoked potentials in the diagnosis of visual pathway disease. Neuro-ophthalmol 1982;2:237-53.

7 Blumhardt LD, Barrett G, Halliday AM, Kriss A. The effect of experimental "scotomata" on the ipsilateral and contralateral responses to pattern-reversal in one half-field. Electroencephalogr Clin Neurophysiol 1978;45:376-92.
8 Carroll WM, Mastaglia FL, Thickbroom GW. The topography and origin of central and peripheral subcomponents of the half-field pattern reversal visual evoked potential (VEP). Neurosci Lett 1985a;Suppl 19:S50.

9 Lorente de No R. A study of nerve physiology. Stud. Rockefeller Inst Med Res 1947, part 1, vol 1.

10 Tasaki I, Singer I, Takenaka T. Effects of internal and external ionic environment on excitability of squid giant axon. A macromolecular approach. J Gen Physiol 1964;48:1095-123.

11 Toffaletti J, Bowers GN. Improvements in and clinical utility of a continuous-flow method for routine measurement of dialyzable (ultrafiltrable) calcium. Clin Chem 1979;25:1939-43.

12 Schain RJ. Cerebrospinal fluid cation levels. Arch Neurol 1964;11:330-3.

13 Gilmore RL, Kasarskis EJ, McAllister RG. Verapamilinduced changes in central conduction in patients with multiple sclerosis. J Neurol Neurosurg Psychiatry 1985;48:1140-6.

14 Young RSK, Yagel SK. Cerebral physiological and metabolic effects of hyperventilation in the neonatal dog. Ann Neurol 1984;16:337-42.

15 Rasminsky M. The effects of temperature on conduction in demyelinated single nerve fibres. Arch Neurol 1978;28:287-92.

16 Persson HE, Sachs C. Provoked visual impairment in multiple sclerosis studied by visual evoked potentials. Electro-encephalogr Clin Neurophysiol 1978;44:664-8.

17 Bajada S, Mastaglia FL, Black JL, Collins DWK. The effects of induced hyperthermia on visual evoked potentials and saccade parameters in normal subjects and patients with multiple sclerosis. $J$ Neurol Neurosurg Psychiatry 1980;43:849-52.

18 McDonald WI. Pathophysiology of multiple sclerosis. Brain 1974;97:179-96.

19 Carroll WM. Visual evoked potential studies in the detection, natural history and pathophysiology of visual pathway demyelination. MD Thesis, University of Western Australia, 1985.

20 Carroll WM, Jennings AR, Mastaglia FL, Levick WR. Conduction in single nerve fibres in experimental demyelinative optic neuropathy. Electroencephalogr Clin Neurophysiol 1985;61:S178.

21 Carroll WM, Jennings AR, Mastaglia FL, Levick WR. Conduction abnormalities in single nerve fibres during the evolution of experimental demyelinative optic neuropathy. Neurosci Lett 1986;Suppl 23:S35. 